recommendations for hydrallazine therapy and previous evidence. ${ }^{13}$ One report is consistent with our experience. ${ }^{5}$ Autoimmune phenomena were also more frequent in asymptomatic slow acetylators receiving $200 \mathrm{mg}$ hydrallazine a day or less. This has previously been reported only in patients taking over $200 \mathrm{mg}$ hydrallazine daily. ${ }^{2}$

Our study indicates that conventionally "safe" doses of hydrallazine may cause both asymptomatic autoimmune phenomena and a lupus syndrome which is not always mild or transient and may require steroids. Potentially serious hydrallazine toxicity is a possibility in all patients taking this drug even after many months of uncomplicated treatment, but especially in slow acetylators in whom constant vigilance for early symptoms is necessary.

Correspondence should be addressed to Dr R F Bing, Department of Medicine, Clinical Sciences Building, Leicester Royal Infirmary, Leicester LE2 7LX.

1 Perry HM. Late toxicity to hydrallazine resembling systemic lupus erythematosus or rheumatoid arthritis. $A m \mathcal{F}$ Med 1973;54:58-72.

2 Perry HM, Tan EM, Carmody S, Sakamoto A. Relationship of acetyl transferase activity and antinuclear antibodies and toxic symptoms in hypertensive patients with hydrallazine. F Lab Clin Med 1970;76: 114-125.

3 Editorial, Hydrallazine. Lancet 1977 ; :342-3.

4 Schroder H. Simplified method for determining acetylator phenotype. Br Med F 1972 :iii:506-7.

5 Boman G. Hydrallazine-induced lupus, reported to the Swedish adverse drug reaction committee. Symposium: pharmacological and clinical aspects of hydrallazine (Apresoline) in today's treatment of hypertension. Ciba Publication, 1977:147-52.

(Accepted 28 April 1980)

Department of Medicine, University of Leicester, Leicester

R F BING, MB, MRCP, lecturer in medicine

G I RUSSELL, MB, MRCP, clinical research associate

H THURSTON, MB, MRCP, reader in medicine

J D SWALES, MD, FRCP, professor of medicine

\section{Neonatal systemic candidiasis treated with miconazole}

Fortunately systemic candidiasis is uncommon in the newborn baby. Amphotericin B may be used only with caution because of the risks of severe side effects, particularly on the kidney. In this case study we describe our experiences with another antifungal agent, miconazole, an imidazole derivative widely used in adults but to our knowledge rarely used in the neonate.

\section{Case report}

A baby girl, birthweight $890 \mathrm{~g}$, was born after 26 weeks' gestation. Between day 3 and day 11 she developed recurrent neonatal apnoea which was managed in turn by intermittent mask ventilation, continuous positive airways pressure, and intravenous aminophylline. On day 6 total parenteral nutrition was started by a central Silastic catheter introduced through a scalp vein. On day 9 the baby became unwell, and Staphylococcus epidermidis was isolated from blood culture. The Silastic catheter was removed and nasogastric feeding and flucloxacillin begun. On day 21 apnoeic episodes recurred, and she was again given parenteral nutrition. Intravenous chloramphenicol was started.

On day 16 Candida albicans was isolated from the mouth and groin and the baby was treated with oral and topical nystatin. $C$ albicans was then isolated from blood culture taken on day 21 . The minimal inhibitory concentration of miconazole for the $C$ albicans isolates was determined by dilution tests in broth and recorded as the lowest antifungal concentrations that gave total inhibition of growth after 48 hours at $37^{\circ} \mathrm{C}$. The minimum inhibitory concentration for miconazole was $25 \mathrm{mg} / 1$ but partial inhibitory effects were noted in vitro at much lower concentrations.

The central Silastic catheter was withdrawn, but Candida was not grown from the catheter tip. Nasojejunal feeding was begun. On day 28 an indurated area on the left thigh was seen to be discharging a large quantity of pus from which $C$ albicans was later isolated. Chloramphenicol was discontinued, and a course of intravenous miconazole was started at a daily dose of $10 \mathrm{mg} / \mathrm{kg}$ given in two divided doses, each lasting two hours. The baby's general condition improved, and the candida abscess showed signs of resolution. A serum miconazole concentration measured within one hour of administration of $1.6 \mathrm{mg} / \mathrm{l}$ was determined by bioassay. On the fifth day of treatment, however, frequent episodes of ventricular tachycardia were noted and miconazole was discontinued.

On day 40 the baby once again became ill. There was persistent purulent discharge from the abscess on the left thigh and a similar abscess had now developed on the right thigh from which $C$ albicans was isolated. Blood culture was sterile. Intravenous miconazole was restarted but, because the drug had an irritant effect on the veins which caused frequent venous thrombosis, oral miconazole was added, and the thigh abscesses were irrigated with the intravenous preparation of the drug. During this second course the serum concentration of miconazole was $2.8 \mathrm{mg} / 1$. Intravenous miconazole was continued for six days, and the thigh abscesses were irrigated for 12 days. Over this time the abscesses healed.

\section{Comment}

We encountered two major problems with miconazole. The first was an intermittent ventricular tachycardia. This has been reported in adults after rapid injections of a bolus (manufacturers' data), but in our baby it occurred between infusions: it is interesting that the problem did not recur during the second course of treatment. Clearly it is unwise to administer miconazole intravenously without facilities for heart-rate monitoring. The second problem was frequent superficial thrombophlebitis at the site of intravenous administration which resulted in considerable practical difficulties in giving the recommended dose of miconazole.

At the end of an intravenous infusion of a therapeutic dose of miconazole blood concentrations in most patients are between 1 and $10 \mathrm{mg} / 1 .{ }^{1}$ The concentrations of serum miconazole in our baby were in this range, and we gained a strong impression that clinical improvement was due to miconazole. With a minimum inhibitory concentration of $25 \mathrm{mg} / \mathrm{l}$ it might be argued that the improvement was coincidental. Nevertheless, it has been suggested that azole antifungal minimum inhibitory concentrations in vivo do not necessarily correlate with effective doses, ${ }^{2}$ and our experiences tend to support this notion.

Correspondence should be addressed to Dr D P Davies.

1 Symoens J. Clinical and experimental evidence on miconazole for the treatment of systemic mycoses : a review. Proc $R$ Soc Med 1977;70:Suppl $1: 4-8$.

2 Odds FC. Problems in the laboratory assessment of antifungal activity. Postgrad Med F 1979;55:677-80.

(Accepted 29 April 1980)

Neonatal Unit, Leicester Royal Infirmary Maternity Hospital, Leicester

M CLARKE, MB, MRCP, senior house officer

D P DAVIES, MD, MRCP, senior lecturer

Department of Microbiology, University of Leicester

F ODDS, BSC, PHD, lecturer

Public Health Laboratory, Leicester

C MITCHELL, MB, MRCPATH, consultant microbiologist

\section{Impotence in diabetic and non-diabetic hospital outpatients}

Although the reported incidence varies greatly, impotence is widely accepted as being more common in diabetics than the general population. Since the Kinsey Report ${ }^{1}$ is the only source giving the incidence in the general population by age, we undertook a small survey of impotence in men attending a diabetic clinic compared with nondiabetic hospital outpatients.

\section{Patients, methods, and results}

We studied 83 consecutive male patients aged 15-60 years attending this clinic and 50 non-diabetic patients within the same age range attending hospital outpatient follow-up clinics in the same area. All answered a short questionnaire about their libido and potency or, if they did not have a sexual partner, whether they experienced morning erections; the non-diabetics were also asked whether, if their sexual performance was unsatisfactory, they had any condition that might cause this. We did not validate the questionnaire, and relied on the patients' own assessments of their sexual performance. 